\title{
Unernste Psychiatrie
}

C. Müller

Eugen Bleuler (1857-1939), Professor der Psychiatrie in Zürich, ist wohl der berühmteste Schweizer Psychiater. Mit seiner Schizophrenielehre hat er 1911 ganz neue Wege beschritten und wurde international berühmt. Nach den Zeugnissen seiner Schüler und Zeitgenossen pflegte er einen spartanischen Lebensstil, Schalk und Narreteien waren ihm fremd. Er war ein radikaler Kämpfer gegen den Alkoholismus. Diesen Kampf hat er sich als Hauptverdienst angerechnet. So erstaunt es nicht, wenn die Mitarbeiter 1923 anlässlich seines Jubiläums die Zügel etwas lockern wollten und ein phantasievolles Menu entwarfen. $\mathrm{Zu}$ den Einzelheiten:

Dr. Ulrich von der Anstalt für Epileptische hat die Bromtherapie für Epileptiker in Form einer Suppe (Sedobrol) eingeführt. Dass der Basedow auf einer Störung der Schilddrüse beruht, ist bekannt. Den Marquis de Sade hat man wohl erwähnt, weil im psychoanalytischen Denken der Sadismus einen wichtigen Platz einnimmt. Kahlbaum war einer der ersten, welcher das katatone Syndrom beschrieb. Regensdorf ist die Zürcher Strafanstalt. Pikant ist, dass "Vins des caves Bleuler» vorgeschlagen wurden.

\footnotetext{
Literatur

- Müller C. Wer hat die Geisteskranken von den Fesseln befreit? Bonn: Edition das Narrenschiff; 1998.

- Schweizerische Epilepsieklinik (Hrsg.). 100 Jahre Schweizerische Epilepsieklinik. Zürich; 1986.
}

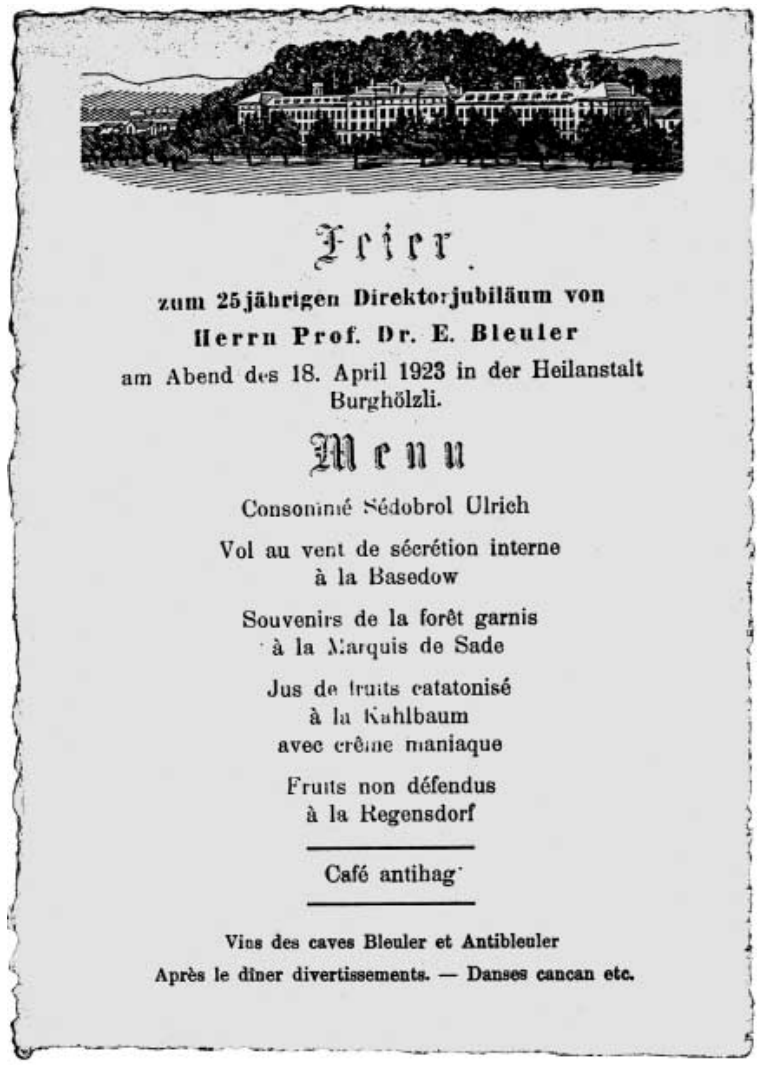

Original, im Besitz von Prof. Dr. med. Christian Müller, Bern.

Korrespondenz:

Prof. Dr. med. Christian Müller

Herrengasse 23

CH-3011 Bern 